\title{
Erratum to: TIVA for Neurosurgery
}

\author{
Andreia Martins Costa and Francisco Lobo
}

\section{Erratum to:}

Chapter 13 (page 155) in: Z.H. Khan (ed.), Challenging Topics in Neuroanesthesia and Neurocritical Care, DOI 10.1007/978-3-319-41445-4_13

\author{
Affiliation of Dr. A.M. Costa was incorrect: \\ Department of Anesthesiology, Centro Hospitalar Lisboa Central, Lisbon, Portugal \\ e-mail: martinsdacosta.andreia@gmail.com
}

The correct affiliation is given below:

Department of Anesthesiology, Centro Hospitalar Lisboa Norte, Lisbon, Portugal e-mail: martinsdacosta.andreia@gmail.com

The online version of the original chapter can be found under DOI 10.1007/978-3-319-41445-4_13

\footnotetext{
A.M. Costa $(\triangle)$

Department of Anesthesiology, Centro Hospitalar

Lisboa Norte, Lisbon, Portugal

e-mail: martinsdacosta.andreia@gmail.com

F. Lobo

Department of Anesthesiology, Hospital Geral de Santo António - Centro Hospitalar do Porto, Porto, Portugal
} 